\title{
Inventing Voice of Identity through L2 Poetry Writing: A Construct of Mindfulness-Based Strategy in Remote Learning
}

\author{
Kadek Sonia Piscayanti \\ Universitas Pendidikan Ganesha \\ sonia.piscayanti@undiksha.ac.id \\ Issy Yuliasari \\ Universitas Negeri Semarang \\ issy.yuliasri@mail.unnes.ac.id
}

\begin{abstract}
Voice of identity can be found in an expressive writing such as poetry writing. In 12 learning context, poetry is a medium to learn a new language in a creative way. Language is developed through mindfulness and creativity. As language develops, 12 learners make use of their sensitivity to language and create or produce the language that represents the voice of identity themselves. This article focuses on how 12 poetry writing can invent voice of identity in the 12 learners by using the construct of mindfulness-based strategy. In the pandemic context where offline education is not possible, mindfulness-based strategy is best implemented in 12 remote learning since it has four main principles in language learning such as finding novelty in learning, being sensitive to context, actively engaged in the present moment, and stimulate opennes and multiperspectives. By online learning, poetry is taught with mindfulness concepts and they are guided mindfully on how they become language learners creatively and effectively by writing their poetry about their life during the pandemic. The data collected are poetry and reflection diary and analyzed through the construct of poetry in mindfulness framework. The results indicated that poetry writing can represent voice of 12 learner's identity; their new perspectives of the world, reflection and sensitivity to context, choices of life, present moment engagement, opennes and multiperspectives
\end{abstract}

Keywords: _poetry, mindfulness, voice, identity, language learning

\section{INTRODUCTION}

The concept of mindfulness was firstly introduced by Ellen J Langer in 1989. The core principles of mindfulness are discover the new things and make new distinctions. The essence of mindfulness process in noticing new things and drawing novel distinction are built from the flexible state of mind. When mind is flexible, the new things are entering the mind and novelty can be found. This practice of mindfulness is revelant with the L2 language learning in the sense that L2 is the new language that is learned by the students. By having mindfulness concept the idea of accepting new things becomes the core of language learning. However the process is not only a matter of accepting new things but also learning to make a novel distinction, how it is different from the language learned previously, how it is possible to be done and how it is built from within the learners.

According to the theory of language there are three approaches to learn language namely the environmentalist approach, innatist approach and interactionist approach. In environmentalist approach, language is treated as a behaviour to be taught. In this approach, language is considered as habits and learners are exercised through the habitual actions. According to Moafian et.al (2019), the environmental approach presented the strategies of how children learn some basic principles of language. However this approach could not give solution to children how to learn difficult grammar. 
In innatist approach, language is built within the learners through Language Acquisition Device. In this approach, learners are the subject of learning in the sense that they are using different mental strategies to meet the system in the target language (Moafian et.al, 2019). The learners are stimulated to use their minds to see, to reflect, to analyze, and to produce. However this approach neglects the function of language and how it is operated in the process of learning.

In interactionist approach, according to Halliday, language is the means of communication. There are three functions of language. First, the interpersonal function which means the language is used to communicate with others. Second, the ideational function which means language is used to communicate the ideas. Third, textual function in which language is used as linguistic tool of ideational and interpersonal functions to make texts both verbal and written (Moafian et.al, 2019).

Mindfulness, on the other hand, is a new concept in language learning that covers all the principles of language learning. Langer's conceptualization of mindfulness have been elaborated previously. The two core principles are noticing new things and finding novel distinctions. In the context of language learning, the two principles are the main keys to learn second or foreign language. But other than those two are engagement and flexibility. The other two relate with the interaction with the other language users and also to be flexible with the context of communication. These four principles are the main foundations in language learning, because language is in a dynamic state of development. One should be actively engaged and flexible on communication.

Mindfulness has become a key in learning process. To be able to learn, mindfulness takes place at the first stage. In the context of language learning, one can access language and understand language only if they are mindful. In this context, L2 is accessed when learners are able to accept new language with the new system that allows them to process new language and respond them. It is also a room for drawing novel distinctions in the sense that it becomes a new knowledge in their mind. In this research, poetry is used as a tool and medium of expression to reveal voice and identity. Poetry, in this L2 learning is a gate way to introduce the new language to L2 learners. Through poetry also their voice of identity is revealed. Poetry is used as a medium to explore creativity and productivity. Mindfulness strategy is used to build a bridge between the language learners and the L2. However, the use of poetry and mindfulness in L2 language learning in the pandemic has rarely been studied. In this context, poetry is used to be a medium of learning L2 by using mindfulness. The voice of identity is revealed through poetry. The novelty of this research is that the mindfulness is used in poetry writing to reveal the voice of identity especially in the remote learning context within the pandemic of covid 19.

Mindfulness leads language learner to find themselves and to develop self-awareness, then to language awareness. Self-awareness develops the language awareness because it stimulates sensitivity, curiosity and creativity. Mindfulness strengthens the process. Mindfulness is proposed by Ellen J. Langer (1989). There are two major foundations of Mindfulness according to Langer. First of all, being aware of something new. Second, giving attention on a unique difference. According to Langer, mindfulness is diversed based thinking and context bound (Davenport and Pagnini, 2016). When we are in a mindful state, we can think in diversity, to many different contexts, to many different solutions, to many points of views (Langer, 1993).

Mindfulness can be applied to many different contexts. In this state of mind, we accept new things, different point of views, new contexts. The awareness of novel point of views will promote new findings, to reconstruct the previous established knowledge and point of views. In this context, learning English as a foreign language is learning something novel, new. If learners are introduced or exposed to new things, new perspectives and new context, it is likely that they are capable of making meaning in a more interesting and involving way. According to Moafian et.al (2019) by having a courage to find novelty in everything, the language learners can 
welcome any new things and information and adapt them in the storage of the brain. One of the new patterns and information can be gained through language.

Poetry in this context is a product of literature that can be used to hear the learner's voice of identity. As Perrine (1982) stated that poetry is a multi-perspectives way of saying things, emotionally, intellectually, and imaginatively. However in this context, poetry is seen as a product of literary text that symbolizes learners' voice of their experience and thoughts.

The structure of poetry are built from lines, stanzas, and figurative languages such as metaphors, imagery, irony, hyperbole, vision and voice. They are selected carefully and arranged beautifully. Therefore the creative process of poetry is never easy. A research by David I Hanauer in 2012 showed that there are four principles that he used to make language learning happens naturally. First, by autobiographical writing, second by emotional writing, third by personal insight, and fourth by authentic public access. His findings show that ESL/EFL literacy instruction based on these prinsiples produces a very different educational experience. The students are directed to really express and explore themselves. The main purpose is to help students extend their language by using their true personal expression. This makes language experience as a personal, emotive and expressive resource. However this article does not explain in detail how the language learning happens from the participant's perspective. In fact, this is the real things that should be explored.

Second, a study done by Shapiro (2001) who found that poetry and mindfulness are medicine of language learning because poetry and mindfulness together create peacefulness, calmness, and positivity. In this research the students are given alternatife to learning, that they are allowed to listen, feel, and discover in different ways. However this article doesn't give much information about the students' perspective on their learning.

In 2016, Atsushi lida conducted a research on how to portray voice of identity in second language haiku. The study found that the identity of the students is revealed through the haikus they wrote, from which they communicate their life stories. The voice can be heard, felt and valued as human's life experience and perspectives. It also revealed the use of poetry as a means of literacy learning.

In 2020, Piscayanti et.al conducted a research on mindfulness in Poetry writing class. This research revealed that mindful learning is very effective to be applied in Poetry class since it promotes self-awareness through the mindful journal. Poetry is used as a voice of identity. As a student wrote, "From mindful learning in poetry I learned that I have ways to express myself better." This voice is very honest about how the learner perceived poetry as expression channel.

A creative process of poetry is never easy. A research by David I Hanauer in 2012 showed that there are four principles that he used to make language learning happens naturally. First, by autobiographical writing, second by emotional writing, third by personal insight, and fourth by authentic public access. His findings show that ESL/EFL literacy instruction based on these principles produces a very different educational experience. The students are directed to really express and explore themselves. The main purpose is to help students extend their language by using their true personal expression. This makes language experience as a personal, emotive and expressive resource. However this article does not explain in detail how the language learning happens from the participant's perspective. In fact, this is the real things that should be explored.

Second, a study done by Shapiro (2001) who found that poetry and mindfulness are medicine of language learning because poetry and mindfulness together create peacefulness, calmness, and positivity. In this research the students are given alternative to learning, that they are allowed to listen, feel, and discover in different ways. However this article doesn't give much information about the students' perspective on their learning.

In 2016, Atsushi Iida conducted a research on poetic identity in second language writing. The study found that the identity of the students is revealed through the haikus they wrote, from 
which they communicate their life stories. The voice can be heard, felt and valued as human's life experience and perspectives. It focuses on poetry writing as a tool of meaningful learning in EFL classroom.

The gap between previous research with the context of this research is that L2 poetry writing as a voice of identity is rarely studied. Actually, poetry in L2 context is a representation of learners' voice. This a tool where the voice of identity can be represented. The novelty of this research is to explore voice of identity that is born from mindfulness learning. Therefore this research tries to explore how voice of identity is revealed through L2 poetry writing. The benefits of this research are as follows. First, by knowing the voice of identity, the learners can learn to know themselves better and language is produced personally, contextually and meaningfully. Second, the benefit of this study can be used as a sample to teach poetry in L2 learning context especially in revealing the voice of identity.

\section{METHODS}

The research design of this study is qualitative research with narrative inquiry method. This method was used to record human experiences through their personal stories (Webster \& Mertova, 2007). In this research context, the voice of identity is explored through poetry. Mindfulness intervention in the creative process helps to stimulate the voice of identity to be heard.

\section{Respondents}

The respondents are 10 EFL learners in poetry course in English Language Education Ganesha University of Education taught by mindfulness. They were chosen through purposive sampling technique. The research object is poetry writing from which voice of identity can be identified, analyzed and interpreted.

Instruments

The instruments used are writing journal, poetry, and three poetic analysis combined with the construct from mindfulness framework.
Data collection procedures

The procedures of research are as follows. First, mindfulness intervention was given during the creative process of poetry writing, which covers three stages namely pre-writing, whilst writing and post-writing. In this research, students poets are given mindfulness treatment in remote learning mode in order to stimulate their thinking. In the process, the students were given series of stimulation on how they perceived moments and experience in their life which relate to their voice of identity. The students are given free writing stages to create narration of their life (past, present, and future moments). The second was to reflect on their narrative and to choose the best moment and poetic experience to be explored more. The last stage is to produce the poetry from which they have reflected their voice of identity inside.

\section{Data analysis}

According to Hanauer's (2010 in Iida, 2016) methodological guidelines for poetic identity investigation. The data analysis was categorized under three classes of analysis namely context of writing, content and literary choices.

The first category is the context of writing. In the L2 learning, context is very important. It helps the students to understand where the language is produced and how it is produced. According to Hanauer (2012) the process of language learning involves their responses to understanding of contexts. The second category is content analysis. According to Hanauer (2010 in IIda, 2016) the poetic identity includes the content in the poem such as chronological moments, inspirations, feelings, and thoughts. This is to consider what is the content presented, why is it presented and how it is presented. The third category is linguistics analysis of figurative language. Poetry writing represents the idea to construct meaning through language. These categories then combined with the construct of poetry with mindfulness framework which is formed by categories of novelty in learning, being sensitive to context, actively engaged in the present moment, and stimulate opennes and multiperspectives. 


\section{FINDING AND DISCUSSION}

From the analysis of the poetry from three categories combined with mindfulness framework there are some important voices that are born from the L2 poetry writing in this research. First is the new perspective of the world voice in which the voice is born from the search of identity to the self. Mindfulness is used as intervention when the poetry is written in many stages which helps the construct of voice revealed in the poetry. Second, the reflection and sensitivity to context. The voice of reflection can be heard from poetry since the identity can only be felt if they are reflected from the sensitivity to context. Third, choices of life. How life is viewed and how perspective is built are the voices of identity that can be brought into the meaning of life. Choices of life are there to show that identity exists in the voice of poetry. The last is openness and multiperspectives voice which help to construct the identity in many different points of views.

\section{New perspective of the world}

New perspective of the world is the core principle of mindfulness strategy which is used wisely in L2 poetry writing process. It is stimulated through stages of writing. The following is a poetry which can be used as an example of representing the voice of identity, in this context is building new perspective of the world.

\section{Childhood}

(Student 1)

When I was child I want to be an adult

I can be free

I can go everywhere I want

I can do everything I want

I can buy what I want to buy

But when I grow up

I feel that being an adult is not that beautiful as I imagine

I feel that being an adult is boring

I feel that being an adult is like a bird in a

cage

Trapped in responsibility
I want to go back to my childhood

When I have much time to play with my

friend

When I do not have to think about my future

Now it is just a memory

A memory of my childhood

A memory just to remember

Here we can see that the student wants to make a new perspective of the world. His idea can be read from the content, that he previously wanted to be an adult. Yet now he is in adulthood, but he wants to have his childhood back. What happens in the adulthood that he wants to bring back the world to childhood world. The idea of comparing childhood and adulthood is to gain new perspective within the writer's self. Adulthood is an area of identity search. Readiness to face adulthood is the issue. However, he could not escape from the childhood that is trapped in his memory, of freedom, of playfulness, of many beautiful carefree memories. The world of adulthood on the other hand, built a new perspective on how different it is with the expectation he has.

The mindfulness process to reveal the voice of poet is clear here because this poetry can not be born alone without his understanding of himself as adult who wants to be back to childhood. The mindfulness process while writing this is started with reflection on the past and present, continued to the future. The choice of language use here is direct and simple. Not metaphorical and poetic, because the issue brought is adulthood versus childhood that needs more direct choice of words.

In 2016, Davenport and Pagnini found that mindfulness practice include observation, articulation, and presentation stimulates students to be aware of the various ways that can be made to a spesific alternative and the possible answers to any issue. In this poetry, observation is done within self in which he reveals the comparison between childhood and adulthood in such a way. Articulation and presentation through poetry is a perfect choice to reveal the voice. 


\begin{abstract}
L2 learning to contrust identity appears in the poetry writing since identities are multiperspectives, dynamic, and constantly reconstructed through interaction of community in real engagements. Adulthood is perceived as a result of community interaction which forms identity of being adult. Wenger (1998 in IIda, 2016) stated that learning is contextual and our identity have been shaped through the participation in community.
\end{abstract}

Another poetry which builds the new perspective of the world is as follows.

\section{No, Believe}

(Student 2)

No

There's a stone for the things forgotten

And you won't look back on

When you choose the one without choice

Ask, believe the rain

It'll dissolve the stone where the forgotten things was hidden

No

The leaves' acapela promise to bring back yours

The leaves' chanting will spin and open your handcuffs

They raise up you from drowning

Lonely

Being a stone

No

This poetry is a unique perspective about stone and its mystery. The poet is trying to give voice of how memories and histories are kept in a stone. Stone is a metaphor for history that is kept and hidden. Sometimes it can be seen sometimes it is still hidden. Sometimes the rain erased it. The voice that the poet offers here is the possibility of many, when the stone is treated as dead thing, or when the stone is respected as memory keeper. The nature here supports the idea of mystery around the stone.
However the voice of nature and stone here are presented with non-judgmental perspective, as it can be read at the ending "lonely/being a stone/no//" which means that the poet does not want to clearly define whether the stone is mistaken or not. Mindfulness is the state of being aware of the present moment, without reflection on the past and without the anticipation of the future nor to solve problems neither to prevent the unpleasant factors of the present. This goes along with the research by Teasdale (1995 in Tarrasch, 2015) which found that mindfulness is the state of being aware of the present moment, without the need to criticize or evaluate the moment, and without judgment. The voice of this poetry reveals the nonjudgemental perspective of the world. In this context, L2 voice of identity is revealed through mindful attention to the nature, the context and the sensitivity to capture the meaning behind everything including stone. This finding is supported by a research in 2016 by Wang and Liu who found that mindfulness can be cultivated and benefits L2 learners in relation to their foreign language learning.

\section{Reflection and Sensitivity to context}

Reflection and sensitivity to context are essentials in L2 learning context. In poetry writing, the two are stimulated through mindfulness based strategy and resulted in poetry as below.

\section{Stressed Out}

(Student 3)

When the rain falls again

I am made like I am in blindness

Everything cannot be seen

Even you hide, might be behind the curtain

Everything is out of mind

For the first time I am made helpless

Even my breath is hard to get out of my nose

It makes me hopeless

Like I am being cursed

I am trapped and stressed

There is nothing I can hope

I beg whoever it is

Helped this poor human 
Get me out of this torture

And God that is watching me

Please crush this situation

To make me escape the tightness of this atmosphere

From this poetry it can be seen that sensitivity to context is very deep. In the beginning it is written "when the rain falls, I am made like I am in blindness". What voice is he trying to speak about. What made this happens. The context of rain, which made him feel trapped, stressed, and tortured can be the metaphor of his problem, his voice of insecurity and his hope to be helped out of the problems. Poetry helps his voice out of the deep chaotic feeling.

The style of language is not metaphorical yet more natural as a conversation to God. The ideas are represented through denotation rather than connotation. However this does not decrease the essence of poetry, since the meaning can be created mindfully. Mindfulness happens here since the voice is naturally expressed and presented. According to Hanauer (2012), L2 learning happens because every personal experience is expressed and the natural voice of poetic identity is heard. Poetry allows this authenticity happens. Therefore L2 language learning happens naturally.

In 2020, Stevenson found that as mindfulness is framed an inner intelligence, it is not a result of observational learning, but a result of our internal intelligence system. However it should be activated, stimulated and developed.

\section{Choices of Life and Present moment engagement}

The choices of life and present moment engagement are very important in the voices of identity in L2 learning context.

\section{Talk}

\section{(Student 4)}

I just want to talk

Talk about everything I want

I just want to share my thought

Petrified mind in the brain

Can I talk now?

Please listen to my heart
Can you hear that?

I hope you can

But why am I speechless when I am with you?

I am a statue when I am with you

The wind is not dare enough to whisper on

my ears

my mouth seems tightly sewn

Oh God how can I talk with him?

Please give me a way to talk with him

I just want to say my deep feeling

No matter what happens

In this poetry the poet wants to share the needs to talk, the voice to express herself and her thought, however it seems to be silenced when the poet comes with the man. This simple poetry does not come with many metaphors, instead the poet use denotation more rather than connotation. The choice of life and the engagement with present moment is more real with the simple language than with the metaphoric language. With this arrangement, the poet chooses her voice to be as clear and direct as possible, avoiding the figurative language.

The identity of the poet is revealed clearly because she has used the language to express her voice. According to Hanauer (2012), when you use the second language as a tool to represent your voice as ideas and experiences, it changes the perspective of language. This is the point where L2 is a tool and becomes a personal touch and an 'originally-owned' language. Though the language is simple and not metaphorical, but the idea of 'owned' language happens, therefore the students' language acquisition must be better if taught by mindfulness and introduced with poetry writing.

Mindfulness leads to freedom of choices and this is very important in L2 learning. In 2011 Sherretz did research and shows consistency with Langer research (1997) who found that mindfulness matters in the sense that when freedom of choice is given and information is different, the individual is forced to be mindful observer.

\section{Openness and multi-perspectives}

Openness and multi-perspectives are also the principles of mindfulness which is very 
relevant to the voice of identity in L2 learning. The poetry which shows this is as follows.

\section{Eternity of love (Student 5)}

You are my moonlight Illuminate every dark knights

Like a flickering starlight

Which adorns the vastness of the dark sky

Your softness is like a pure white cloud

Your smile is like the morning sun

Illuminating the bottom of the heart

Your faithful never fades even though time is getting worn out

Your charm is like a flower that blooms when spring arrives

Become a colour for the world

My world that never feels empty

Thanks to your presence

Which always soothes the heart

No day passes without a spark of your warm love

All stumbling blocks are in the way

Will not be able to change everything I feel to you

Even one day

Your body is no longer here

The one I want to believe

Your eternal love will always accompany you

Either you or I first met that destiny

Don't worry about it

Let's hold hands tight

Wade through this river of life together

In this poetry the poet wants to be open and speak about her voice to thank her lover of his presence. The voice of identity as a partner in love clearly be seen from the choice of words, lines and stanzas. The feeling is expressed directly and openly without much metaphoric expressions. The openness and perspective that is built within this poetry is simply understood by the simple lines and stanzas.

From this poetry, it can be understood that emotional identity of the poet is revealed. Mindfulness in this context happens naturally to deal with emotional intelligence. In 2017, Cotler et.al found that there is a significant effect on the growth of emotional intelligence by combining both direct instruction and mindfulness. L2 poetry here is an example of how voice and identity can be stimulated through mindfulness. According to Hanauer (2016) poetry has the power to make L2 meaning making practice much intimate, individual and close. It allows L2 writers to invent themselves during the process.

Another poetry that can reveal the emotional identity is this poetry.

\section{Old Wounds (Student 6)}

I'm not the one who is wrong

He is also not wrong, but you

You made all this

make old wounds come again

Your diatribe imprint on the heart

It is okay, if it makes you good

You always see everything like trash

It is okay, if it makes you happy

You always underestimate someone Because your money goes blind

Because of the position, you become deaf

Even ties have become dust

But you remember...

Wealth and position will not last long

who you think of as rubbish

Some time you will also become trash

The voice of opennes can be felt here, however the voice is like a blame on someone. The perspective of the poet is like a victim of action committed by the subject referred to in the poetry. The linguistic perspective is sharp, cynical, and sarcastic. The language use is full of emotions, 
with condensed composition. This is a result of mindful process of writing.

According to Langer and Moldoveanu (2000) mindfulness can cause awareness of the present, build sensitivity to context, and stimulate diversity. This strengthens Langer's ideas that this multipoint of views decreases our tendency to refer to the past. In 2020, McKay and Walker found that mindfulness had a powerful positive link with positive mental health, personal happiness and positive character. This can lead to creativity and productivity.

It goes along with Piscayanti (2017) who found that Mindful Learning is very effective to be used in Poetry class because it has the power to make learners more sensitive, productive and innovative. The students are encouraged to invent their own language on their self-contexts. Cooper and Boyd (1996) in Wang and Liu (2016, p.143) proved that mindfulness promotes new things, innovative dynamic learning. This finding is strengthened by Davenport and Pagnini (2016) who found that Mindful Learning can help learners to have innovation, invention, creativity, and collaboration power.

\section{CONCLUSION}

This article focuses on how L2 Poetry Writing can invent voice of identity in the L2 learners by using the construct of mindfulness. The results indicated that poetry writing can represent voice of L2 learner's identity; their new perspectives of the world, their reflection and sensitivity to context, their choices of life and present moment engagement, opennes and multiperspectives. Voice of identity is stimulated and engaged in a direct interaction with the mindfulness within self, in which the L2 learners learn to hear the voice of themselves, trying to figure out what feeling is that, how they are constructed and how they are presented through poetry. Furthermore it is the process to 'own' the language through poetry writing. The moment when L2 learners can produce poetry in L2 is the moment where they really "produce" their own language.

The current study was done with very limited exploration of how the poetry becomes the invention of L2 language and how that happens.
However this study convinced that L2 poetry writing can be an effective tools to be used to present the unheard voices and identities of L2 learners. In the future it needs more exploration on how mindfulness can deepen and sharpen the productivity of L2 in terms of poetry writing.

\section{REFERENCES}

Cotler, J. L. et al. (2017). A mindful approach to teaching emotional intelligence to undergraduate students online and in person. Information Systems Education Journal (ISEDJ), 15(1).

Davenport, C. and Pagnini, Francesco. (2016). Mindful learning: a case study of langerian mindfulness in schools. Front. Psychol. 7:1372. http://dx.doi.org/10.3389/fpsyg.2016.01372.

Hanauer, D. I. (2012). Meaningful literacy: Writing poetry in the language classroom. Plenary Speeches, 45(1), 105-115.

Iida, A. (2016). Poetic identity second language writing: exploring an efl learner's study abroad experience. Eurasian Journal of Applied Linguistics

http://dx.doi.org/10.32601/ejal.460985

Kennedy, X.J. (1983). Literature: an introduction to fiction, poetry, drama. Little Brown and Company

Langer, E. J. (1989). Mindfulness. Library of Congress Cataloging in-Publishing Data.

Langer, E. J., \& Moldoveanu. (2000). The construct of mindfulness. Journal of Social Issues, 56(1), 1 - 9 .

McKay, T., \& Walker, B. R. (2021). Mindfulness, self-compassion and wellbeing. Personality and Individual Differences, 168. https://doi.org/10.1016/j.paid.2020.110412

Moafian, F., Khoshima, H., Fadardi, J.S and Pagnini, F. (2019). Langerian mindfulness and language learning. Educational Psychology and Counselling

Perinne, L. (1982). Sound and sense: an introduction to poetry. Thomas R. Arp. Harcourt Brace Jovanovich

Piscayanti, K. S. (2017). Studi kasus penerapan mindful learning dalam pembelajaran literature 1 di jurusan pendidikan bahasa 


\section{inggris undiksha (research report). Universitas Pendidikan Ganesha. \\ Piscayanti, K.S. (2020). pengaruh penerapan mindful learning terhadap kreativitas dan produktivitas mahasiswa dalam pembelajaran poetry di prodi pendidikan bahasa inggris undiksha. Universitas Pendidikan Ganesha.}

Shapiro, J. (2001). Poetry, mindfulness, and medicine. Literature and the Arts in Medical Education, 33(7).

Sherretz, C. E. ( 2011). Mindfulness in education: Case studies of mindful teachers and their teaching practices. Journal of Thought, FallWinter, 79 - 96.

Stevenson, J. C. et al. (2020). Adult attachment and mindfulness: Examining directionality, causality, and theoretical implications. Journal of Research in Personality, 90. https://doi.org/10.1016/j.jrp.2020.104043

Tarrasch, R. (2015). Mindfulness meditation training for graduate students in educational counseling and special education: A qualitative analysis. J Child Fam Stud, 24, 1322 - 1333. https://doi.org/10.1007/s10826-014-9939-y

Wang, Y., \& Liu, C. (2016). Cultivate mindfulness: A case study of mindful learning in an english as a foreign language classroom. The IAFOR Journal of Education, 4(2), 141 - 155.

Webster, L., \& Mertova, P. (2007). Using narrative inquiry as a research method. Routledge. 